\title{
Scientists given the jitters
}

\section{Washington \& Tokyo}

THE US Department of Defense (DoD), whose network of navigation satellites has recently allowed scientists to determine geographical positions with unprecedented accuracy, has begun intentionally degrading the signals so that potential military adversaries are unable to take advantage of the system. But researchers in Japan and elsewhere say that the real victims of this misinformation could be scientists trying to forecast earthquakes by using the satellites to detect minute precursor ground motions.

The Global Positioning System (GPS), a constellation of two dozen satellites that broadcast signals to ground-based receivers, has been in place since the late 1970s. Each satellite broadcasts a signal that specifies its position and the relative positions of receivers on the ground. Using the signals from several satellites, aircraft, ships and other vehicles can find their position by triangulation to within 40 metres.

But in recent years, researchers have begun averaging many readings over time to find locations with errors of as little as one centimetre (Nature 343, 590 \& 631, 15 February 1990). This accuracy makes GPS measurements useful for seismology: movements in the Earth's crust in the weeks before an earthquake can translate into positional changes of several centimetres, and by monitoring the relative positions of GPS receivers that have been placed around likely trouble spots, researchers may be able to predict impending earthquakes by watching for unexpected changes in positions.

When the GPS system was first launched in 1978, these sorts of precise scientific applications were completely unanticipated. But although the usefulness of the first 'block' of GPS satellites proved to be an unexpected windfall for scientists and other users, the second block of satellites now going up has even greater potential. Indeed, from the beginning, the DoD considered the second generation of GPS satellites too accurate for 'unauthorized' use.

Built into the second-generation GPS satellites are electronics that slightly alter the transmitted signal to cloak the true position of the satellite. 'Authorized users' have been given equipment that can unscramble the distortion to reveal a satellite's exact position at any time. Known as 'selective availability' (SA), this method has been in use for about a month.

For unauthorized users - a group that includes most scientists - the effect of SA is that signals that could be trusted to provide $1 \mathrm{~cm}$ accuracy a month ago are now only good to about $6 \mathrm{~cm}$. Although
SA has been planned for years and the DoD issued warning notices several months ago, many researchers were nevertheless caught off-guard by the sudden signal degradation in March.

US researchers are appealing to GPS officials to reverse the policy. The American Congress on Surveying and Mapping is asking the DoD to treat SA as a trial programme, and argue that researchers should have access to the full GPS accuracy in times of peace, saving SA for outbreaks of hostilities. But until the DoD reconsiders $\mathrm{SA}$, the best solution, suggests one researcher, is to "write [to] your congressman". DoD officials are considering several alternatives that may appease the scientific community. One solution would be to allow researchers to apply for authorized-user status, so that they could be given access to special decoding equipment. But it is not clear what criteria would be taken into consideration when judging such applications.

Scientists may find that more readings over a longer period of time will give full GPS accuracy, officials say. Or research teams can take data they know are somewhat incorrect, then wait several weeks for the DoD to issue corrected satellite positions from which fully accurate positions can be calculated. But a wait of several weeks is too long for most earthquake forecasting, says Yukio Fujinawa of the National Research Centre for Disaster Prevention in Tsukuba, near Tokyo.

Fujinawa's work monitoring crustal movements for earthquakes and volcanic eruption predictions, requires accurate broadcast data "within a few hours", he says. If the United States retains the SA system as is, prompt predictions based on crustal movement will be "practically impossible".

Because of the increasing importance of satellite positioning data in seismology and the sudden loss of precise data from the GPS system, some Japanese researchers are proposing that Japan should launch its own satellite system. Others suggest assembling an international network of monitoring stations that could, by comparing data, form better estimates of the GPS satellites' true positions. But such a network would probably take several days to provide positions of the accuracy that Fujinawa needs, and for disaster predictions, he adds, a wait of several days may be several days too long.

G. Christopher Anderson \& David Swinbanks

\section{SCIENTIFIC MISCONDUCT}

\section{Dingell tries again}

\section{Washington}

Representative John Dingell (Democrat, Michigan) tried once again, last Monday, 14 May, to establish with the help of forensic evidence from the Secret Service that part of the data in a 1986 Cell paper by David Baltimore, Thereza Imanishi-Kari and others was fabricated. As in a previous hearing last year (see Nature 339, 163; 18 May 1989), Dingell argued that Imanishi-Kari had altered her laboratory notebooks to conceal the fact that key experiments in the paper had never been carried out

But Imanishi-Kari, who refused to appear at the hearing and made her rebuttal at a press conference, responded, as she had done last time, that her only sin was poor note-keeping. Dingell says he intends to turn the evidence over to the Justice Department for possible criminal prosecution.

At Monday's hearing, before Dingell's oversight and investigations subcommittee, two Secret Service agents recounted their analysis of paper tapes from gammaray counters in Imanishi-Kari's laboratory at the Massachusetts Institute of Technology. From examination of the typeface of the printer and the wear on the ink ribbons, they concluded that the order in which the tapes appear in the notebooks is not the order in which they were pro- duced, and that the tapes were not produced on the dates marked on the corresponding notebook pages.

The agents argued that many of the data may have been created after allegations of misconduct first arose in the spring of 1986. But because there is no independent record of when the experiments were actually done, inconsistency between various dates is all the Secret Service has been able to prove.

Imanishi-Kari said last week that she has never disputed that dates in her notebooks may not correspond with experiments. She said she sometimes transcribed experimental notes into the notebooks months after the experiments were over. The dates "could mean the day the experiment began, or the day it finished. If I had a better record I would put it forward. But that is how I take notes."

Suzanne Hadley, former director of the National Institutes of Health (NIH) office of scientific integrity, told the hearing that $\mathrm{NIH}$ have cut off funds for one of two grants to Imanishi-Kari because of "significant questions about her ability to hold a grant". But she added that that does not imply that NIH has determined misconduct; improper record-keeping is also a grant-losing offence.

G. Christopher Anderson 